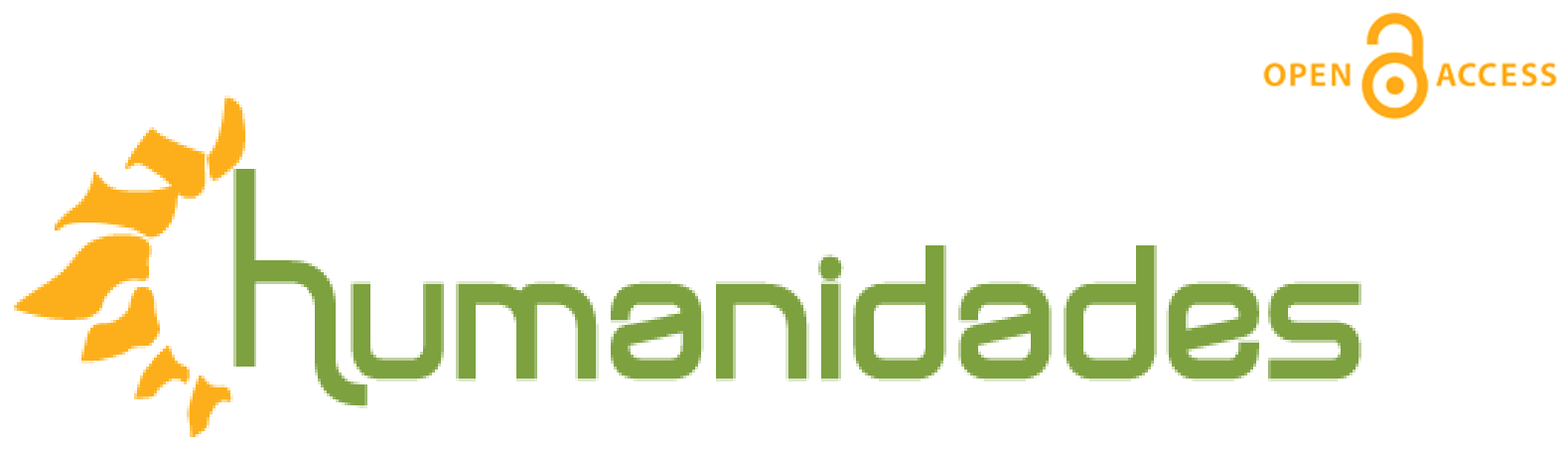

Revista de la Escuela de Estudios Generales, Universidad de Costa Rica

Julio-diciembre, 2016 • Volumen 6, número 2 • EISSN 2215-3934• pp. 1-7

\title{
Proceso relativo y Tha (Grabados)
}

DOI: http://dx.doi.org/10.15517/h.v6i2.26751

\section{Alejandro Porras Zamora}

Estudiante, Bachiller en Diseño Gráfico con énfasis en Diseño de Estampa, Universidad de Costa Rica.

Correo electrónico: alepoza70@ gmail.com

Todos los derechos reservados. Universidad de Costa Rica. Esta revista se encuentra licenciada con Creative Commons. Reconocimiento-NoComercial-SinObraDerivada 3.0 Costa Rica.

Correo electrónico: humanidades@ ucr.ac.cr / Sitio web: http://revistas.ucr.ac.cr/index.php/humanidades 


\section{Proceso relativo y Tha (Grabados)}

Proceso relativo (litografía) y Tha (mezzotinta) son obras realizadas por medio de dos técnicas del grabado. Si bien ambas suponen complejidades en su proceso, su construcción, como imagen y proceso, continúa siendo la exploración misma de la mancha y del espacio vacío... como elaboración recurrente en la ambigüedad de su significado. 


\section{Proceso relativo}

La obra litográfica se realizó, en este caso, de manera experimental, a través de una lámina hidrofílica que permite trabajar adecuadamente con agua, dejándola pasar entre su superficie por medio del poro. Esta, además, al secar es muy receptiva a la grasa, por lo que, a manera de litografía (como técnica) cumple a cabalidad con la división del agua y aceite.

La lámina se prepara limpiándola con agua y jabón cuidadosamente, de esa forma, eliminar cualquier rastro de suciedad. Lo anterior a modo de preparación para una impresión digital. La tinta que se adhiere, por medio de la impresión digital, a la superficie porosa de la lámina, toma el papel de la imagen ya fijada en la piedra, según la técnica litográfica. A partir de eso, continúa el mismo proceso de entintar la lámina, someterla al agua e imprimir. Los resultados varían sustancialmente a medida que la impresión continúe. 


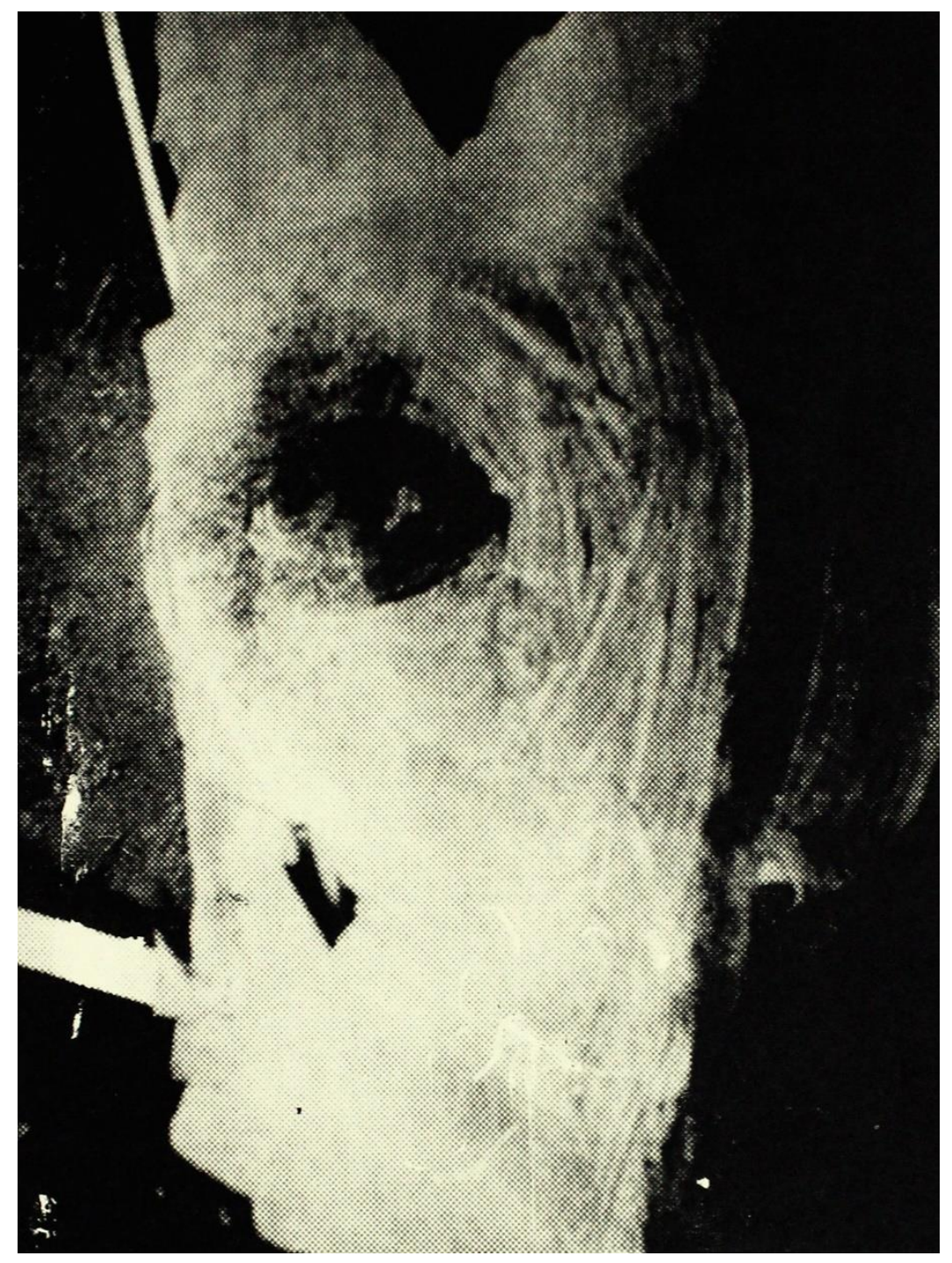

Figura 1. Proceso relativo. Litografía experimental (polímero hidrofílico), 28 x $21 \mathrm{~cm}$. 


\section{Tha}

En el caso de la mezzotinta, esta técnica de grabado en metal (que aún perdura) proviene del siglo XVIII, como solución técnica para la reproducción de alto nivel de pinturas y como precursora de la fotografía. Así como la litografía experimental, la mezzotinta guarda un grado de complejidad, en este caso, al preparar la placa metálica. Con ayuda de una herramienta denominada rascador, toda la placa se corruga, poco a poco. Dicha herramienta deja un aspecto en la superficie metálica... como abierta, rasgada en minúsculos trazos, de los cuales se obtiene una tonalidad única de negro y cuyos blancos o matices de gris surgen a medida que se la placa se pula por secciones. 


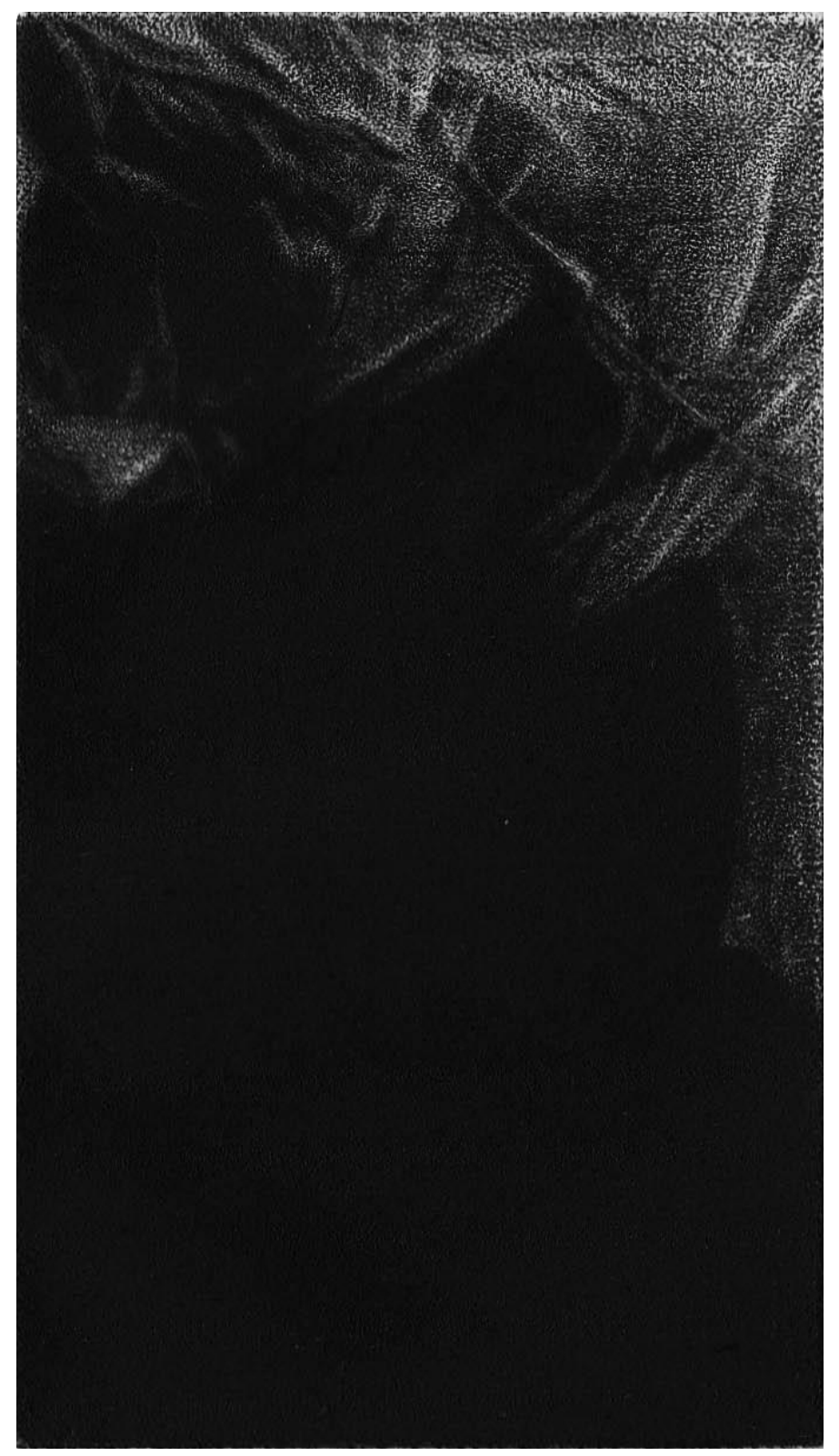

Figura 2. Tha. Mezzotinta, 11 x $6 \mathrm{~cm}$. 
Ambas obras, Proceso relativo y Tha, comprenden el continuo proceso de elaborar zonas amplias, por medio de un elemento indefinido, a partir de la mancha y de formas que convergen en la composición. El multisignificado que pueda existir o no en cada obra se propone siempre por medio de una libre lectura que se pueda realizar del espacio ocupado por una mancha o una línea. Se distancia, a modo placentero, de un parámetro de análisis común que pretenda familiarizar cada forma con algo más distinguible. Dialogan ambas ante los extremos del reconocimiento y la frialdad del límite inexistente, en cuyo caso promulgamos continuarlo para darle nombre y lugar.

\section{¿Cómo citar este artículo?}

Porras, A. (Julio-diciembre, 2016). Proceso relativo y Tha (Grabados). Revista humanidades, 6(2), 1-7. doi: dx.doi.org/10.15517/h.v6i2.26751 